\title{
Essential Factors in Valuation of Oil Properties*
}

\author{
By Carl H. Beal, $†$ M. A., San Francisco, Calif.
}

(Chicago Meeting, September, 1919)

THE most important factors that should be given consideration in the valuation of oil lands are: (1) the amount of oil the property will produce; (2) the amount of money this oil will bring (based upon the future prices of oil); (3) development and production costs; (4) the rate of interest on the investment; (5) the retirement or amortization of invested capital; and (6) the salvage or "scrap" value of the equipment when the property is exhausted. These factors are of varying importance and some of them may not enter all valuation problems, but most of them should be given consideration in any valuation even though only a rough estimate of the value of the property is desired.

The value of a property may be changed over night by the completion of important test wells, by the sudden water flooding, or by a change in the price of oil. The best a petroleum engineer can give is the value of the property under the conditions existing at the time the appraisal is made with a fair forecast of future action of the wells and of the price of oil.

Our experience in the scientific valuation of oil lands is not broad and there is very little published information on the subject; it, therefore, becomes necessary in studying such problems to form comparisons with the factors involved in the valuation of mines-the closest parallel. One of the reasons for the lack of substantial progress in oil-land valuation methods has been the necessity of making an estimate of the future production of the oil property to be valued. Oil men and accountants have not generally conceded that such estimates could be made with any degree of accuracy. It has been shown, however, in several recent publications that with certain data available reasonably close estimates can be made. The accuracy of an appraisal depends chiefly on the accuracy of the estimates of future production and of the future price of oil. The accuracy of the former is sometimes necessarily based on geological inferences. Geology is not an exact science and geological data in connection with oil production cannot always be mathematically evaluated.

* Published by permission of Director, U. S. Bureau of Mines.

$\uparrow$ Petroleum Technologist, U. S. Bureau of Mines. 


\section{Future Oil or Expectation}

In considering the factor of future oil, two related questions must be answered: How much oil will the property produce? At what rate will the oil be produced? If we can determine the future annual production of an oil property, we may easily determine the total future production by addition, so we will consider only the question of rate of future oil production.

A satisfactory answer to this question is the keynote to the whole valuation; for, although our work, has, by no means, been completed after the question has been disposed of, the work of determining the value of the property is greatly simplified, for on the yearly output of oil depends the yearly gross income. From the gross income the annual net return is computed, each year's return being considered in the light of a profit available at a future date. The present value of these deferred profits is then determined by discounting them at a rate of interest compatible with the risk involved.

No uniform yearly revenue can usually be expected from an oil property, for the annual output, and thus the annual income, depends on the rate of production. Only under exceptional conditions can a steady oil production be maintained for long unless the property is old and production well settled. The future annual oil output hinges on the rapidity with which new wells are drilled and on the rate of production of the individual wells which, with very few exceptions, always declines.

Rate at Which Oil Will Be Obtained.- The rate of production of the wells will affect not only the rate of output of the old wells, but will regulate that of the wells to be drilled. Furthermore, the decline in the initial output must be considered; the longer the development of the proved acreage is deferred, the less will be its ultimate production, for, under usual conditions, the wells on the drilled acreage cause a decrease in gas pressure over the undrilled acreage, which results in decreased initial production of the wells eventually drilled there. The rate at which oil wells will produce is the resultant of many complex factors, which will not be discussed here. For more information on this subject, the reader is referred to a bulletin by the author. ${ }^{1}$

The most trustworthy method of determining the rate of production of the wells of a group is to prepare a production curve that will give the average yearly output of wells of different initial yearly output. It is necessary to determine this for wells of different initial production, because wells of different output decline in production at different ratesother factors being equal.

${ }^{1}$ Carl H. Beal: Decline and Utimate Production of Oil Wells with Notes on the Valuation of Oil Properties. U. S. Bureau of Mines Bull. 177 (1919). 
Drilling Program.- The rate of the production of the property depends not only on the rate at which the individual wells will produce oil but also on the rapidity with which new wells are added to the producing list; this depends on the drilling program. The valuation should not be attempted until a drilling program is decided upon. But before a drilling program can be determined, it is necessary to know the amount of land that certainly will support commercially productive wells; trustworthy estimates of future oil production can be made only for the drilled acreage and for the undrilled proved acreage. Only such land furnishes a concrete basis of value, for the annual production of oil can be estimated; other land has a speculative value that varies with the uncertainty of obtaining oil in commercial quantities. These tracts, if included, should be valued separately and on a different basis.

Although there is no case exactly parallel in metal mining, the metalmining engineer refuses to commit himself on the value of a prospective mine. The petroleum engineer may determine the magnitude of the risk and compute mathematically the probability of obtaining oil on a tract of land; but the author is inclined to agree, in a measure, with Rickard" that "the doctrine of probabilities has been stultified too often to allow of its being stated as a scientific thesis."

In valuing the proved oil land, the engineer should compute the value of the output of the property based on a drilling program that will bring the maximum return in profits to the investor. It is true that a variation in the drilling program sometimes will greatly reduce the profits eventually gained from a property, but there can be only one maximum value and this is the one to be determined.

\section{Classification of Land to be Valued}

Before the future annual production can be estimated, it is necessary to classify the land to be valued, to determine the amount of acreage that will support new wells. For this purpose the land is first divided into drilled and undrilled. These two classes of acreage must be valued separately.

Estimating the future production of the old wells usually is not difficult, if production curves are available. Our greatest difficulty lies in making estimates of the probable future production of the proved undrilled acreage. Here we must be guided by underground geologic conditions and by what the new wells probably will produce by comparing the conditions under which they are to produce with the conditions under which the nearby old wells are producing. The undrilled oil

2T. A. Rickard: Valuation of Metal Mines. International Engineering Congress, 1915. 
land may usually be divided into the following four general classes: Proved acreage, probable acreage, prospective acreage, and commercially non-productive acreage. Some engineers use much more detailed classifications. These, the writer believes incompatible with the uncertainty of underground conditions. The following definitions are advanced tentatively:

Proved acreage should include that in which drilling involves practically no risk. The following definition is proposed, which has been modified from that given by R. P. McLaughlin. ${ }^{3}$ "Proved oil land is that which has been shown, by finished wells supplemented by geologic data, to be such that other wells drilled thereon are practically certain to be commercial producers."

Probable oil land includes those areas generally adjacent to producing oil and gas wells where the existence of oil is not proved, but where geologic evidence indicates a good chance of obtaining oil in commercial quantities.

Prospective oil land includes those areas usually not adjacent to producing oil and gas wells, where the existence of oil is not proved, but where geologic data justifies drilling a test well. Land in this class is distinguished from the probable oil land by the greater uncertainty of obtaining oil owing, usually, to its location some distance from producing oil and gas wells.

Commercially non-productive oil land is that on which commercially productive wells cannot be drilled at present. The existence of oil under the areas of this class may be proved, probable, or prospective.

Exceptions undoubtedly will be found in every class. For instance, under some conditions, a person may feel warranted to place land in the probable class when it is favorably located geologically, even though it is several miles from producing wells, for the reason that the occurrence of oil and gas with relation to certain geologic structures in that region may be so certain as to make the chance of not obtaining some oil very small. Furthermore, the classification of land may change rapidly, owing to the drilling of new wells, damage by water, or change in price. For example, an area that may be rated as commercially non-productive may become commercially productive and proved with an increase in the price of oil.

\section{Future Price of Otl}

The accuracy of any valuation depends on the price that is to be received for the oil, for on it depends the net profit per barrel of oil marketed. A small variation in the price of oil may mean the difference

${ }^{3}$ R. P. McLaughlin: Petroleum Industry of California. California State Mining Bureau Bull. 69 (1914) 13. 
between gain or loss. In fact, since the working out of new and more trustworthy methods for more accurately estimating future oil production, the estimation of the future price has become one of the most uncertain elements to be contended with in oil land valuation.

The engineer, to make sound predictions as to the probable price of oil, even during the immediate future, must possess a broad knowledge of the petroleum situation as regards supply and demand. Either prices will be allowed to adjust themselves in accordance with the law of supply and demand, or they will be manipulated by monopolies or controlled by the Federal Government. If manipulation or government control exists, or if there is a strong probability of their coming into existence, the engineer should be guided accordingly. Otherwise, the question of price must be answered solely by the domestic and foreign oil situation. The past range of prices has often been great, but the future probably will never see such low prices of oil. The market is now more stable because the demand for the commodities made of petroleum is greater and new oil fields are much more scarce and more costly to develop.

The reason for the great demand for oil is primarily because of the great demand for one of its products-gasoline. The great demand for gasoline is created by the phenomenal development of the internalcombustion engine. This development is, probably, by no means, completed. The adoption of oil as fuel by the great navies of the world and the development and adoption of the Diesel engine have greatly increased the demand for the heavier products of petroleum. Very likely the future demand for oil and its products will not decrease.

The upward limit of prices is set by the cost of importing oil and the cost of developing a supply of oil from oil shales, of which there are immense deposits in this country. By considering the status of the industry at the present time and these two limiting factors, the engineer should be able to make reasonably sound estimates of the price of oil for the next few years. Some engineers find it advisable to use the present prices as a basis of estimating the value of the property or to determine the value of the property at several different prices of oil, and thus allow the investor to select the one that, in his judgment, will best meet future conditions.

\section{Cost of Production and Development}

In determining the future net receipts from each barrel of oil, the cost of producing the oil must be subtracted from the gross income or selling price. For the purpose of estimating future production costs, including drilling charges, tankage, and, in fact, every charge that contributes to the final total cost of production, the appraiser should refer to trustworthy statistics and should be able to interpret these statistics in 
terms of probable future conditions. This, again, requires not only a broad knowledge of the oil industry but also detailed knowledge of costs in the locality where the property is situated.

\section{INTEREST ON INVESTMENT}

The proper rate of interest to be received from an investment must be such that capital will be attracted to the enterprise. If the risk attached to the investment is great, the rate of interest on the money invested must be high or investors cannot be found. The returns from oil investments are always speculative to some degree, so the interest demanded is usually high. If there is no risk, the investor can afford to invest his money at the same rate as if he put it in the savings bank at 4 per cent.

The basis of value in oil lands is net income. The net income for each future year of the productive life of the oil property must be estimated and these future values compared with their real values at the present moment by reducing them to present value at a given rate of interest. This is discount and is the reverse of compound interest, the factor used in the reduction of future values to present values being called the discount factor, which is a very important element in oil-land valuation. By the reverse of discount, or compound interest, the future value of a present income may be determined.

Present value of a future income may be defined as that sum which, when placed at interest at a stated per cent., will equal the income at the date when it is to be realized. Thus, the longer the deferment of an income the less it is worth at the present time, for which reason one can afford to pay more for income to be obtained from the oil from a well drilled now than for the same well drilled a year hence, providing the price of oil remains constant and equal amounts of oil are produced. Furthermore, the longer drilling is postponed the less the net proceeds from the wells are worth to a prospective purchaser at the present time. Other things being equal a property should be drilled as quickly as possible, if the maximum income is to be derived from it. This may not be best from the standpoint of the public, and, if generally practiced by oil producers, would eventually work to their advantage.

The interest required on the investment must be high because risk is attached to the venture. Some engineers consider that the discount used in reducing future income to present value, however, should not be compounded for the reason that to compound a certain present sum to determine its future value means the first year to determine the interest on the principal and thereafter to compute yearly the interest on the principal and accumulated interest earnings. The rate used is a high rate because the capital, or principal, is being risked. This rate 
should not be applied to the accumulated interest earnings, however, because these are not risked capital. They are earnings and should be considered as such.

The computed maximum value of the property may be considerably less than what actually could be paid for the property for as the returns in the investment are realized they may be reinvested in gilt-edged securities at an accumulative rate of interest.

\section{Amortization of INVESTMENT}

In investing in an exhaustible resource, the investor expects not only the return of a certain interest on the investment, but also the return of the principal by the time the resource is exhausted. This is called amortization, or retirement of capital, and may be effected by a sinking fund into which annual contributions are made. The sinking fund may be placed at interest, so that the sum of the annual contributions may not be required to equal the total original capital. Although sinking funds may not be established, some attempt must be made to return capital uniformly and justly, where it is possible to estimate the amount of oil recoverable and the hazard of the investment is not too great to make such calculations useless.

A method often practiced by oil companies to determine the rate of retiring the capital invested in both physical property and in the resource is called the "settled production method," and consists of applying a unit value per barrel of settled daily production. The value of the property at any time is the daily production mutiplied by the unit value. The difference in the value determined at any two periods is the depreciation or appreciation according to whether the value has gone down or up.

A modification of this method for the purpose of determining the depletion deduction in connection with the computing of taxable income, is called the "reduction in flow method." The method has been authorized by the Treasury Department, but obviously is unfair when it is remembered that the basis of the method depends on a reduction in the output of an oil property from the existing wells only. No depletion is allowed and, therefore, no capital is retired unless production is decreasing. If production decreases 5 per cent. during the taxable year, 5 per cent. of the capital invested is retired. During the next year, if the decrease is 10 per cent, that percentage of the unretired capital is "written off." As a general rule, the output of an oil property increases for a few months, at least, while drilling of new wells is in progress, and in some fields, production may increase for several years. Still, by use of this method no capital can be retired until the production of the tract begins to decrease. Production of nil means depletion of its recoverable 
content and every barrel of oil taken from a property exhausts it just that much, and brings it just that much nearer the end of its life. To retire no capital while production is largest and then when production begins to decline, to retire large amounts against a decreasing income not only is inequitable to the oil operator but places the whole enterprise in jeopardy by deferring the amortization to a period when the field is rapidly approaching exhaustion and too late to cover the return of capital.

The producer has made a definite investment in each barrel of recoverable oil. If he can estimate the amount of recoverable oil, he can easily determine the cost per barrel. For every barrel of oil produced, he should retire an amount of capital equal to the original investment in that barrel of oil. This is called the "unit cost method," by which a fixed charge per barrel of oil produced, based on quantity, is assessed. It is sound in principle, not difficult of application, and has been adopted by the Treasury Department in the determination of the depletion deduction in connection with the administration of the income and excessprofits tax laws. This undoubtedly is the fairest and most equitable method of amortizing an investment in a mineral property. The method is suggested in several publications on mine accounting, ${ }^{4}$ so has the added weight of precedence.

The basis of this method is to determine the total capital invested in the oil and then divide the estimated recoverable oil into the capital invested; the result is the unit cost. For instance, if the sum of $\$ 1,000,000$ is invested in the oil under a property, estimated to produce ultimately $10,000,000$ barrels of oil, the unit cost per barrel is $10 \mathrm{c}$. The producer has paid this sum for each barrel of oil under the property. If he sells each barrel of oil for $\$ 1.50$, his net income for each barrel will be determined by deducting all charges from $\$ 1.50$. Suppose all charges, excepting unit cost, amount to $40 \mathrm{c}$. per barrel, his net income is, therefore, $\$ 1$.

Estimates of future production may be revised each year and a new "unit cost" obtained by dividing the unretired capital by the remaining recoverable oil. The amount of capital to retire during that year on account of depletion will be the unit cost multiplied by the production.

Many oil companies have adopted this system because by its use they are enabled not only to determine the depletion deduction equitably and justly, but also because they are enabled to retire the capital investment at the same rate at which the oil is produced. The only unknown factor in the determination of unit cost is the amount of recoverable oil, and 1905.

"F. Hobart in "The Economics of Mining," by T. A. Rickard and others, 223, 
this can be estimated with a reasonable degree of certainty by the use of methods outlined by Lewis ${ }^{5}$ and the author. ${ }^{8}$

Depreciation refers to the wear and tear on physical property and capital invested in it must be retired in addition to the capital invested in the exhaustible resource. The methods of retiring such capital will not be discussed in this paper. The amount retired should be equal to the capital invested minus the salvage or "scrap" value of the equipment.

\section{Salvage Value of Equipment}

When the oil is exhausted, a certain amount of physical property will be on hand. The investment in this physical property should have been completely amortized, with no investment remaining except that which can be realized from the disposal of the equipment. This sum is called the salvage, or "scrap," value of the equipment. Ordinarily this "junk" value is not great at the exhaustion of the oil. Furthermore, the proceeds derived from the sale of the "junk" must be discounted to the time of the valuation at a certain rate of interest. Usually the property will have a life of more than 20 years, and the present value of the junk, even at a comparatively low rate of interest, is rather small when compared with other sources of income that must be present before the investment is a good one. Occasionally, the expenses in connection with the abandonment of the property, such as properly plugging the wells, will cost as much or more than the present value of the junk, so that this item in oil-land valuation is ordinarily not important.

5J. O. Lewis and Carl H. Beal: Some New Methods for Estimating the Future Production of Oil Wells. Trans. (1918) 59, 492.

${ }^{\circ}$ U. S. Bureau of Mines Bull. 177. 